\title{
The Relevance of Fatalism in the Study of Latinas' Cancer Screening Behavior: A Systematic Review of the Literature
}

\author{
Karla Espinosa de los Monteros • Linda C. Gallo
}

Published online: 17 October 2010

(C) The Author(s) 2010. This article is published with open access at Springerlink.com

\begin{abstract}
Background Fatalism has been identified as a dominant belief among Latinos and is believed to act as a barrier to cancer prevention. However, controversy exists over the utility of the construct in explaining health disparities experienced by disadvantaged populations above the influence of structural barriers such as low socioeconomic status (SES) and limited access to health care.

Purpose This paper reviews the empirical research on fatalism and Latinas' participation in cancer screening in an attempt to determine whether fatalism predicts participation in cancer screening after accounting for structural barriers.

Method Google Scholar, ERIC, CINAHL, Medline, PsychINFO, ProQuest, PubMed, and PsychARTICLES were searched for empirical studies published prior to February 25, 2010.

Results A total of 43 articles were obtained and 11 met the inclusion criteria. The majority of studies (64\%) reported a statistically significant association between fatalism and utilization of cancer screening services after accounting for structural barriers. However, mixed findings and limitations in measurement and design across studies preclude clear conclusions about the nature of the relationship.

Conclusion Preliminary evidence for an inverse association between fatalism and Latinas' utilization of cancer screening services after accounting for structural barriers was identified. However, additional research that addresses methodological limitations is warranted to advance our understanding of the
\end{abstract}

K. Espinosa de los Monteros $\cdot$ L. C. Gallo $(\triangle)$

SDSU/UCSD Joint Doctoral Program in Clinical Psychology,

San Diego State University,

9245 Sky Park Court Suite 115,

San Diego, CA 92123, USA

e-mail: lcgallo@sciences.sdsu.edu utility of fatalism in explaining inequities in cancer burden experienced by this at-risk group.

Keywords Cancer · Cultural Beliefs · Fatalism · Ethnic Disparities $\cdot$ Latinos $\cdot$ Women's Health

\section{Introduction}

Inequities in the timeliness and quality of cancer treatment along with the probability of cancer survival experienced by Latinas ${ }^{1}$ regardless of age, stage, and type of cancer highlight the need for public health efforts aimed at reducing the cancer burden experienced by this population [1]. Across all ethnic groups, Latinas experience the highest rate of invasive cervical cancer and related mortality with incidence rates that are almost twice as high as those of their non-Latino White counterparts. Although the incidence of breast and colorectal cancer is lower for Latinas compared to African-American and non-Latino White women, Latinas are more likely to be diagnosed with the disease at later stages, decreasing their chance of survival [1]. To a large extent, such cancer disparities can be attributed to Latinas' underutilization of cancer screening services [2]. Regular cancer screening can greatly improve the chance of survivorship for certain cancers (e.g., breast, colorectal, and cervical cancer). Unfortunately, Latinas exhibit some of the lowest cancer screening rates in the

\footnotetext{
${ }^{1}$ Given limitations in the existing literature on fatalism and cancer screening (e.g., the limited amount of studies that directly measured the relationship between fatalism and cancer screening and the fact that most of the research on the subject has been conducted on females of Latin American descent), this review will focus exclusively on Latinas. However, the reviewed topic is also relevant to males and other ethnic groups, most notably, African-Americans.
} 
USA [1]. Although barriers such as low health literacy and limited access to care certainly play a role in explaining this disparity, fatalism may further explain Latinas' underutilization of these services [3-5].

\section{Fatalism and Cancer Screening}

Fatalism refers to the general belief that all events, and in particular, the actions and occurrences that form an individual life, are determined by fate [6]. When applied to health, fatalism is often operationalized as negative or pessimistic attitudes regarding preventive health practices and disease outcomes. Fatalism has therefore been identified as a potential barrier to cancer prevention and early detection efforts $[5,7,8]$. Racial and ethnic differences in fatalism have been identified, with fatalistic beliefs and attitudes towards health being more common among Latinos and African-Americans compared to non-Latino Whites [9-11]. For example, Latinos are more likely than non-Latino Whites to believe that cancer cannot be prevented and that death is inevitable after diagnosis [12]. Such beliefs are likely to result in few perceived benefits to screening, particularly in light of the material losses (e.g., time, money) and aversive experiences (e.g., discomfort, anxiety) associated with screening. Moreover, one would expect normative pressure to comply with cancer screening guidelines to be low within cultures where fatalistic attitudes towards health are pervasive.

However, the relevance of fatalism in explaining Latinas' screening behavior in the context of social and environmental constraints is unclear. Many scientists have cautioned against identifying fatalism as an impediment to Latino health without considering the numerous material barriers (e.g., low education, poor access to health care, and poverty) encountered by this population $[8,13]$. Philosophical perspectives on fatalism stress that the construct is most accurately conceptualized as a balance between the almost universally valued goal of good health, and the recognition that barriers to health exist that may not be overcome through personal effort [14]. Poverty, racism, discrimination, and inadequate access to education and health care represent important barriers to health-enhancing behaviors $[15,16]$. Thus, for socially disadvantaged populations such as Latinos, fatalistic attitudes towards cancer maybe grounded in reality $[8,17]$. Moreover, poor health outcomes experienced by the disadvantaged will likely reinforce fatalistic perceptions about diseases such as cancer [18]. Thus, if fatalism is merely a reflection of the constraints experienced by disadvantaged populations, intervention efforts will optimally focus on decreasing tangible barriers to cancer screening (e.g., inequitable healthcare access), rather than directly targeting fatalistic beliefs and attitudes of this population.
Purpose

In summary, fatalism maybe an important factor in explaining the underutilization of cancer screening services among Latinas, however, its significance over the influence of social and environmental constraints is unclear. This paper will review the empirical research on fatalism and Latinas' utilization of cancer screening services in order to determine whether fatalism predicts Latinas' participation in cancer screening after accounting for structural barriers such as health care access and SES. In addition, this paper will highlight methodological strengths and limitations across studies to draw conclusions about the quality of the available data and make recommendations for future research.

\section{Methods}

An initial search on Google Scholar, ERIC, CINAHL, Medline, PsychINFO, PubMed, ProQuest, and PsychARTICLES was conducted using the key terms "Hispanic, Hispano, Hispana, Latino, or Latina," and "fatalism, fatalismo, or fatalistic beliefs" and "cancer screening or cancer." The search was restricted to peer-reviewed articles or dissertations written in English or Spanish and published prior to February 25, 2010 (no start date was specified). A total of 38 unique articles or dissertations were identified that included any combination of the key terms from each category in the title or abstract of the paper. The reference lists of the remaining articles were reviewed to identify additional articles that met the initial search criteria for the present review for a total sample of 43 articles. The search was then refined to quantitative studies that directly measured the relationship between fatalism and Latinas' cancer screening behavior after accounting for SES or health care access. Of the 43 manuscripts identified: seven were excluded because they were qualitative studies [19-25]; 18 were excluded because they did not directly measure cancer screening behavior $[8,11,12$, 26-40]; 3 were excluded because they did not directly measure fatalism ${ }^{2}$ or include it as an independent predictor [4, 41, 42]; two were excluded because they did not report results by ethnicity [43, 44]; one was excluded because participants were male [45]; and one was excluded because the authors did not account for SES or health care access in analyses [46] for a remaining sample of 11 studies. Data on each study's design, population sampled, and measurement of fatalism and cancer screening are summarized in Table 1.

\footnotetext{
${ }^{2}$ Although fatalism and locus of control are related constructs, distinct differences have been reported across constructs in regards to philosophical and conceptual underpinnings, dimensionality, and potential implications for health behavior [62-64]. Thus, studies that utilized locus of control scales to assess fatalism were excluded from this review.
} 


\section{Results}

\section{Study Characteristics}

All articles included in this review were evaluated with regard to: study design; characteristics of the sample population; method of assessment of fatalism and cancer screening; and control of confounding factors (e.g., age, SES, access to medical care). All studies assessed and controlled for age, SES, acculturation, and, with the exception of one study, health care access [47]. Seven of the 11 studies reviewed (64\%) reported statistically significant inverse associations between fatalism and the likelihood of cancer screening. However, most of the studies included in this review adopted a cross-sectional design, limiting conclusions about causation. In addition, all studies were conducted on adult female populations that were either exclusively or largely of Latino background, and all reported differences by ethnicity. While all studies measured fatalism, the operationalization and measurement of the construct varied across studies. Finally, all but two studies relied on self-report to assess cancer screening behavior; specifically, eight studies measured cervical cancer screening, seven measured breast cancer screening, and one study measured colorectal cancer screening behavior.

\section{Study Design}

Ten studies implemented a cross-sectional design. Although cross-sectional designs have numerous advantages (e.g., rapid implementation; inexpensive), they do not allow for the establishment of directionality. Thus, from this review one cannot rule out the possibility that the reported associations between fatalism and cancer screening are accounted for by the influence of the behavior itself upon women's beliefs and attitudes towards cancer. However, the two studies from which a causal relationship can be inferred $[48,49]$ suggest that fatalism predicts a likelihood of participating in screening. These results are discussed in more detail below.

\section{Study Populations}

Seven of the 11 studies were based on community samples and implemented some form of random approach to identifying subjects (e.g., random digit dial or stratified area probability sample). Of the studies that did not implement random sampling procedures, one relied on a convenience sample of women newly diagnosed with cervical cancer presenting for gynecological care [48], one sampled women participating in a national breast and cervical cancer screening program [49], one sampled women who had participated in the El Paso Cancer and Chronic Disease Consortium [50], and finally, one sampled women who had been in contact with the Los Angeles County Breast Cancer Early Detection Program [47].

All studies were conducted on adult Latino populations from various regions of the USA, including Orange County, San Jose, San Diego, San Francisco, Fresno, Modesto, Los Angeles, Brooklyn, Miami, Chicago, Phoenix, Manhattan, Galveston, Brazoria, Houston, El Paso, and Matagorda. The country of origin of participants varied across studies with five studies relying on predominantly Mexican-American [10, 13, 51, 52] or Mexican-American and Central American participants [53], two studies focusing on Mexican-American women exclusively [50, 54], and two studies sampling women from the Caribbean [3, 49]. Two of the studies reviewed did not include any information about country of origin $[47,48]$.

\section{Measurement of Fatalism}

There was little consensus in the operationalization and measurement of fatalism across the studies reviewed. Eight of the eleven studies utilized instruments that were either adapted from existing scales [27, 47, 49, 53] or unique to the study $[10,13,51,52]$. Methods of instrument development varied from comprehensive ethnographic interviews [13] to pilot testing of items created by the investigators [54]. Additional instruments utilized include an 8-item fatalism scale created by Cuellar and colleagues [55] and the Powe Fatalism Inventory [18]. All but two of the studies included in the review [47, 54] assessed fatalistic beliefs and attitudes specific to cancer. Representative items for all instruments are included in Table 1.

\section{Measurement of Cancer Screening}

All but two studies relied on self-report to assess cancer screening behavior. Methods of assessment varied. One study relied on written responses [48]; two relied on responses to face-to-face interviews [3, 54]; and six relied on responses to telephone interviews [10, 13, 47, 51-53]. Objective methods of assessing screening behavior included whether or not participants returned a Fecal Occult Blood Test (FOBT) screening kit [49], and medical record abstractions [50]. Additional information on each study's method of assessment is outlined in Table 1 .

Relationships Between Fatalism and Key

Sociodemographic Variables

Of the studies reviewed, six reported associations between fatalism and key sociodemographic variables such as SES and acculturation [10, 13, 48, 51-53]. In general, fatalism 


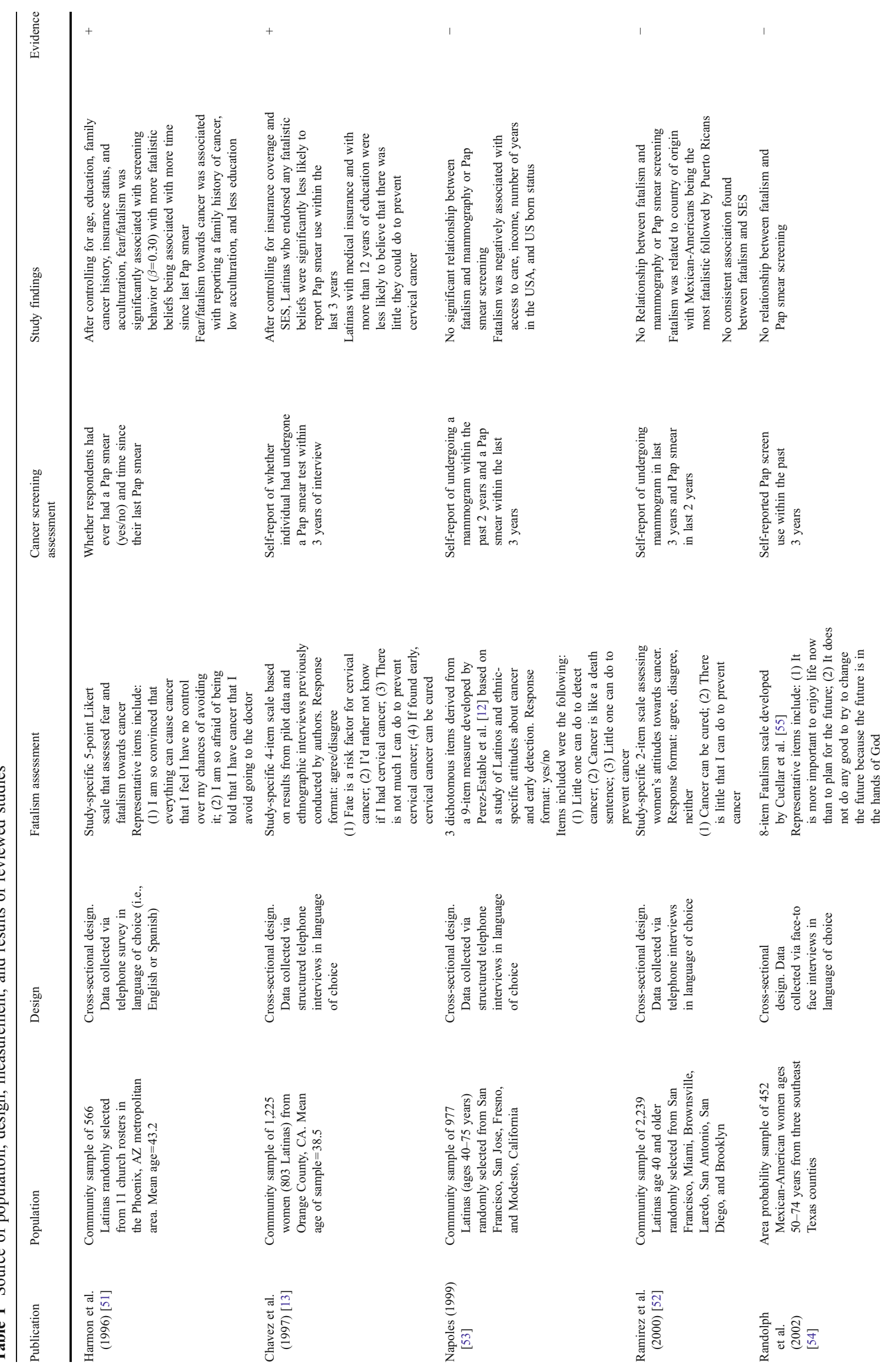



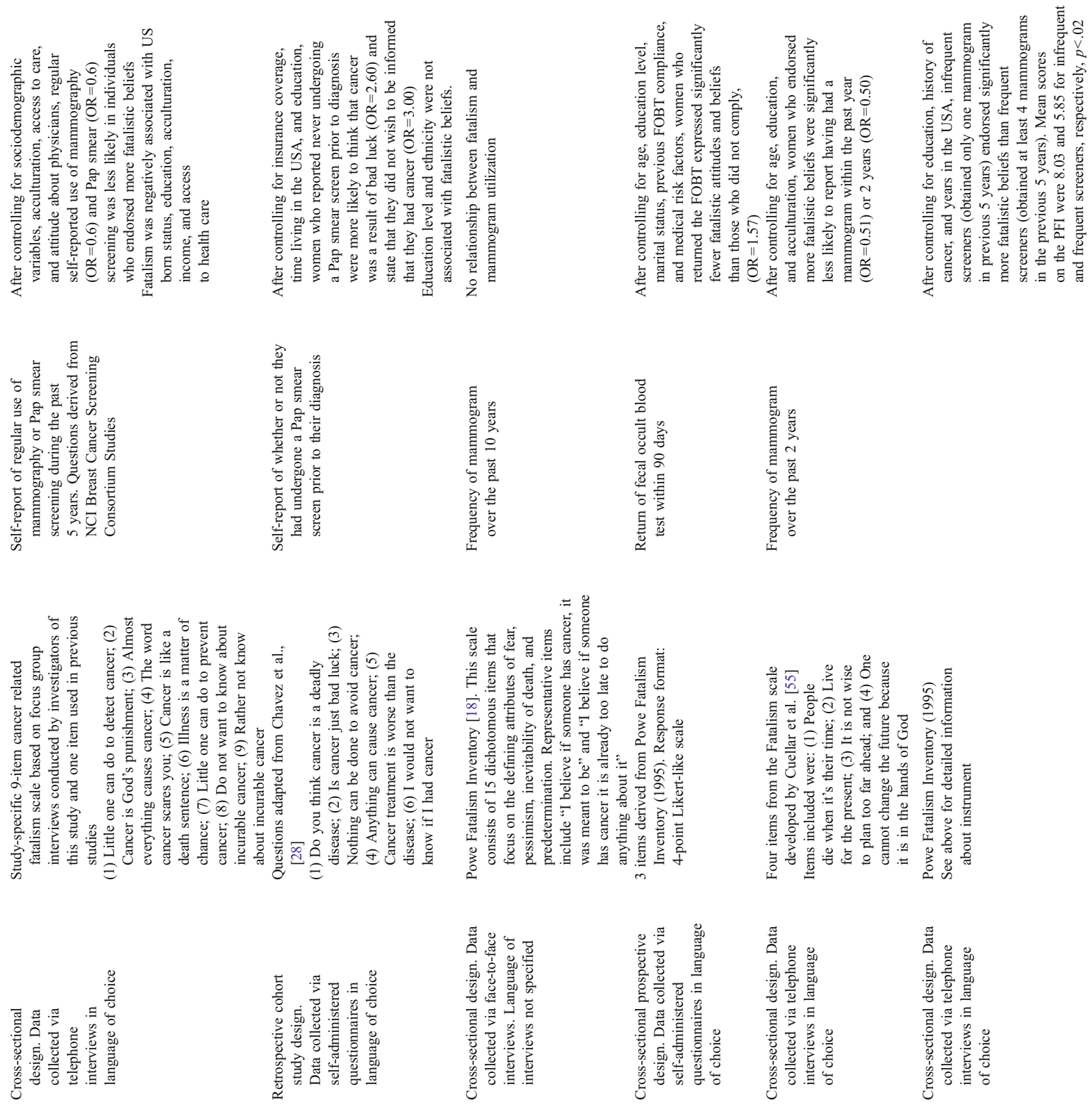

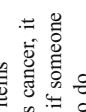

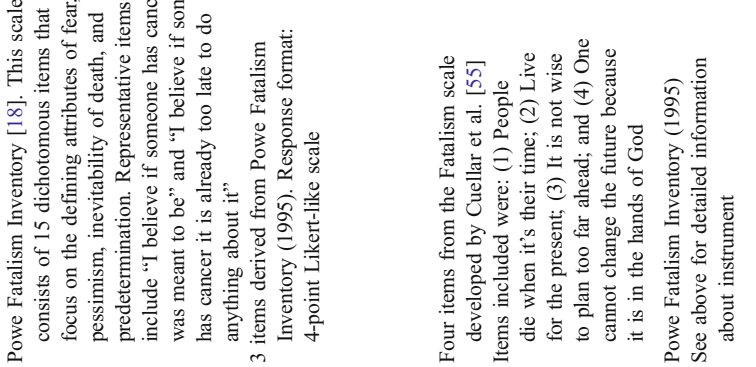

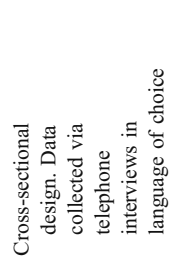
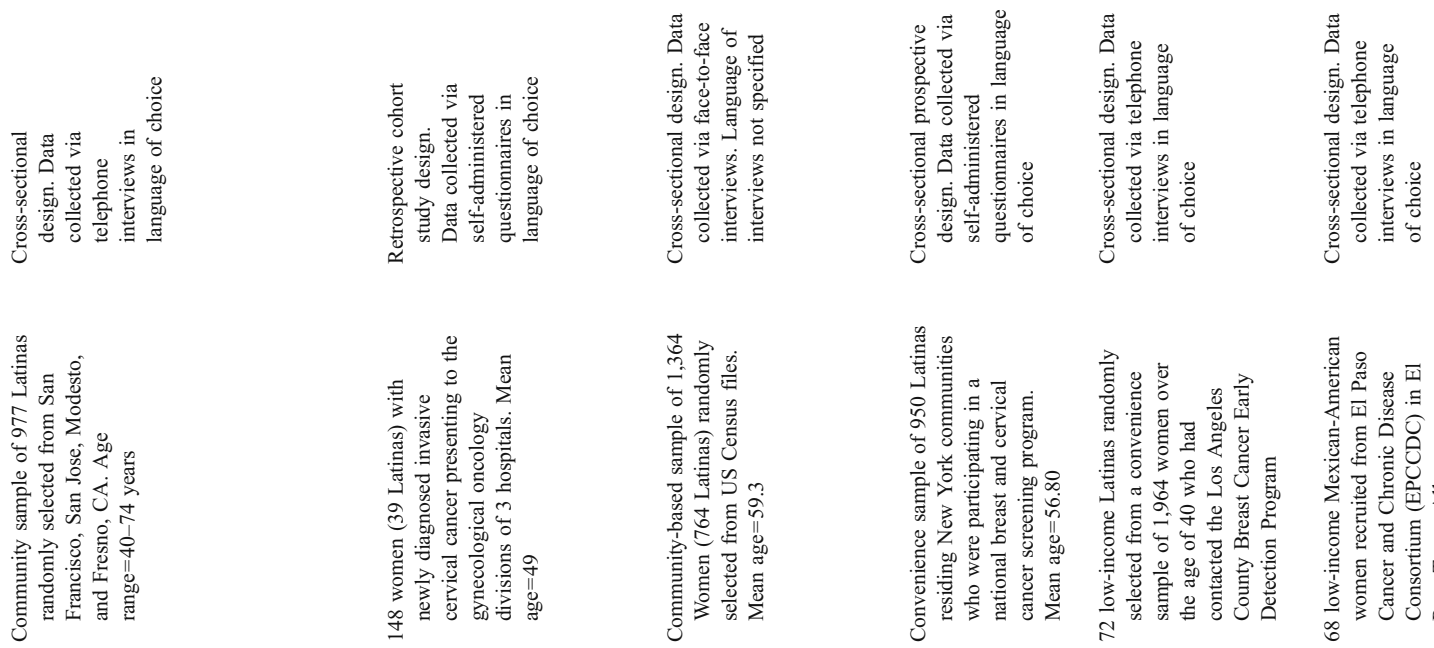

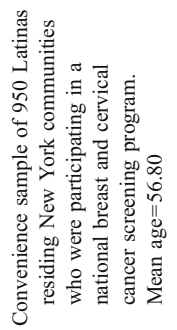

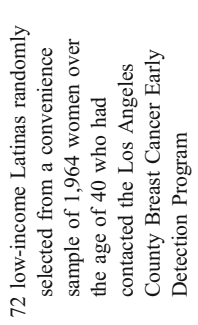

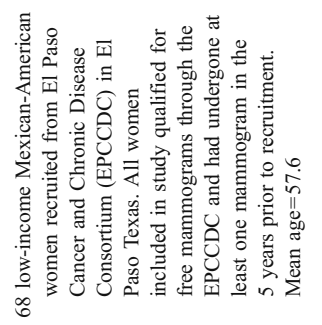

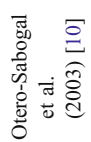

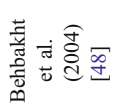

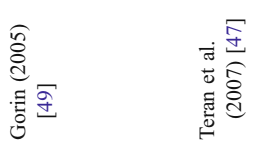

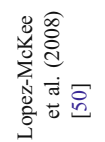


was associated with lower acculturation [10, 51, 53], limited access to health care $[10,13,53]$, and lower education and/or income $[10,13,51,53]$. In contrast, one study reported inconsistent findings for SES and fatalism, with education, income, and health insurance status being significantly associated with decreased likelihood of believing that little could be done to prevent cancer but not associated with the belief that cancer could be cured [52]. Finally, one study reported that individuals who reported a family history of cancer were more likely to endorse fatalistic beliefs [51].

\section{Cervical Cancer Screening}

Seven studies examined the relationship between fatalism and cervical cancer screening. In a sample of church-going Latinas primarily of Mexican-American background, Harmon and colleagues [51] found cancer fatalism to be predictive of time since last Pap smear after accounting for age, education, family cancer history, insurance coverage, and acculturation level. Similarly, Otero-Sabogal and colleagues [10] reported a significant relationship between cancer fatalism and Pap smear maintenance behavior in a sample of Latinas predominantly of Mexican-American and Central American background after accounting for sociodemographic variables, acculturation, access to care, and attitude towards physicians.

In another predominantly Mexican-American sample, Chavez et al. [13] found a significant relationship between cancer fatalism and use of Pap smear screening (within 3 years of assessment) after accounting for insurance coverage and SES. Similarly, in a sample of women newly diagnosed with invasive cervical cancer, fatalism was associated with decreased odds of participating in Pap smear screening prior to diagnosis after controlling for time living in the USA, medical insurance coverage, and education level [48].

In contrast to these findings, three studies found no significant association between fatalism [54] or cancer fatalism [52, 53] and cervical cancer screening after accounting for age, SES, and insurance coverage.

\section{Breast Cancer Screening}

Two studies found a significant association between cancer fatalism and breast cancer screening. Otero-Sabogal and colleagues [10] reported that in a sample of primarily Mexican-American Latinas, those who endorsed more fatalistic beliefs about cancer were at decreased odds of reporting regular mammogram screening after accounting for sociodemographic variables, acculturation, access to care, and attitude towards physicians. Similarly, LopezMckee and colleagues [50] reported a significant, inverse association between fatalism and frequency of mammography screening in a sample of low-income MexicanAmerican women enrolled in a no-cost cancer screening outreach program, after controlling for education, history of cancer, and years living in the USA. In addition, Teran and colleagues [47] found a significant association between high fatalism and lower frequency of mammogram utilization after accounting for age, education, and acculturation. These results were based on a convenience sample of lowincome Latinas who had been in contact with the Los Angeles County Breast Cancer Early Detection Program.

Three studies did not find a significant association between cancer fatalism [52, 53] or fatalism and breast cancer screening [3]. All of these studies controlled for age, SES, and health care access.

\section{Colorectal Cancer Screening}

Only one study investigated the relationship between fatalism and colorectal cancer screening. After controlling for age, education, marital status, previous compliance with colorectal cancer screening, and medical risk factors, women who expressed more fatalism were less likely to return FOBT screening kits after 90 days [49].

\section{Discussion}

One of the major criticisms of research emphasizing the role of cognitive processes in explaining the health behavior of disadvantaged populations is that structural barriers maybetter account for health disparities than cognitive processes which could merely reflect the structural barriers experienced by such populations [8]. The present review addressed this criticism by examining whether fatalism predicted the likelihood that Latinas would engage in cancer screening after accounting for structural barriers. Seven of 11 studies reviewed suggested that after controlling for variables such as age, SES, and access to health care, fatalism may indeed act as a barrier to cancer screening. Four did not find an association between fatalism and cancer screening behavior. Moreover, the literature is characterized by several limitations that need to be addressed before clear conclusions can be reached about the nature of the relationship between fatalism and cancer screening in this population.

Firstly, there is little consensus as to the operationalization of the fatalism construct across studies. For example, in regards to what would be most predictive of health behavior, it is not clear whether fatalism should be conceptualized as a global trait or merely as specific fatalistic beliefs regarding the disease of interest (e.g., cancer fatalism). Efforts to identify the underlying compo- 
nents of fatalism that maybe most important to understanding Latinas' use of cancer screening services are warranted.

Secondly, only three studies included in this review used comparable methods of measurement $[3,44,50]$, making it difficult to compare results across studies. Thirdly, most of the studies reviewed reported aggregate findings across Latinos of diverse origins. "Latino or Hispanic" is a panethnic category that incorporates a diverse group of people with distinct racial, social, cultural, and historical backgrounds $[8,56]$. Panethnic groupings in health research can be problematic because they mask considerable heterogeneity leading to misleading or inconclusive findings [57]. Based on the information provided in this review it is not possible to determine whether fatalism operates differently across Latino subpopulations. However, the fact that established predictors of health outcomes, such as SES, have been shown to operate differently across Latino subpopulations [58,59] warrants efforts aimed at investigating whether the role of fatalism in predicting cancer screening differs across Latino subpopulations. Equally important are efforts aimed at evaluating the validity and reliability of fatalism measures across these diverse groups.

Fourthly, most of the studies to date have adopted crosssectional designs that limit conclusions regarding directionality. Therefore, one cannot rule out the possibility that the observed associations between fatalism and cancer screening maybe better accounted for by the influence of participants' behavior (i.e., underutilization of cancer screening services) on their beliefs about the importance of early detection. Fifthly, the effect sizes reported across studies were small, although the ability to detect the true magnitude of influence of fatalism on cancer screening maybe hampered by measurement error. Finally, as with all literature reviews, the validity of the findings presented maybe compromised by publication bias towards studies with significant findings, results consistent with previous research, or large sample sizes.

In conclusion, although the findings are mixed and additional research is clearly needed, the majority of the studies reviewed reported a significant relationship between fatalism and cancer screening after accounting for structural barriers. This suggests that fatalism could represent a unique predictive factor in relation to this important health behavior. On the other hand, present research is limited by factors that need to be addressed before clear conclusions can be drawn. For example, research is needed to identify the underlying components of the construct that are most pertinent to Latino health. An important question to consider is whether fatalism should be assessed as a global trait or as specific beliefs about the disease in question. In addition, increased consistency in the tools used to measure the construct would facilitate the comparison of results across studies. Such consensus may require more informa- tion regarding the reliability and validity of available instruments, particularly across diverse Latino subpopulations. Efforts to explore the unique influence of fatalistic beliefs across Latino subpopulations inclusive of males are also needed.

As noted above, only one study examined the association between fatalism and cancer screening in a prospective experimental design [49]. Longitudinal research is needed to better understand the temporal relationships among structural conditions, fatalism, and cancer screening behavior. Although beyond the scope of this paper, it is important to note that the relationship between SES, fatalism, and cancer screening maybe more complicated than what is presented in this review. For example, it is possible that fatalism maybe more accurately represented as one mechanism linking SES to cancer screening rather than an independent predictor or confounding factor. In addition, fatalistic attitudes could interact with SES to place certain individuals at greater risk of cancer screening underutilization. Using statistical models that allow for the exploration of more sophisticated hypotheses would help to further enhance our understanding of the relationship between structural barriers, fatalism, and this important health behavior.

Recent research in the contribution of fatalism to ethnic disparities $[5,60]$, and growing evidence that fatalistic beliefs can be changed [61] highlight the importance of understanding the role that fatalism plays in explaining Latinas' cancer screening behavior. Improving our understanding of the importance of fatalism in explaining underutilization of cancer screening services among Latinas may drive the development of more effective and culturally appropriate interventions to reduce ethnic disparities in cancer.

Acknowledgements The research was supported by a Ruth L. Kirschstein National Research Service Award (1 F31 HL087732-02) from the National Heart Lung and Blood Institute, National Institutes of Health (NIH) and by grant number 1P20MD002293-01, San Diego Partnership to reduce CVD Disparities, National Center of Minority Health and Health Disparities, National Institutes of Health. Its contents are solely the responsibility of the authors and do not necessarily represent the official view of the National Institutes of Health.

Open Access This article is distributed under the terms of the Creative Commons Attribution Noncommercial License which permits any noncommercial use, distribution, and reproduction in any medium, provided the original author(s) and source are credited.

\section{References}

1. American Cancer Society. Cancer Facts and Figures for Hispanics 2006-2008. Available at: http://www.cancer.org/ downloads/STT/CAFF2006HispPWSecured.pdf. Accessed 20 January 2009. 
2. Ramirez AG, Suarez L, McAlister A, Villareal R, Trapido E, Talavera GA, et al. Cervical cancer screening in regional Hispanic populations. Am J Health Behav. 2007;24:181-92.

3. Magai C, Consedine N, Conway F, Neugut A, Culver C. Diversity matters: unique populations of women and breast cancer screening. Cancer. 2004;100(11):2300-7.

4. Arredondo EM, Pollak KC, Philip R. Evaluating a stage model in predicting monolingual Spanish-speaking Latinas' cervical cancer screening practices: the role of psychosocial and cultural predictors. Health Educ Behav. 2008;35:791-805.

5. Powe BD, Finnie R. Cancer fatalism: the state of the science. Cancer Nurs. 2003;26(6):454-65.

6. Fatalism (n.d). In Oxford English dictionary. Available at: http:// dictionary.oed.com. Accessed 8 September 2010.

7. Schwab T, Miaskowski C, Merrell R. Measuring attitudes and health beliefs among Mexican Americans with diabetes. Diab Educ. 1994;20:221-7.

8. Abraido-Lanza AE, Villanueva Cruz IJ, Florez KR, Cespedes A, Aguirre AN, De La Cruz AA. Commentary: fatalismo reconsidered: a cautionary note for health-related research and practice with Latino populations. Ethn Dis. 2007;17:153-8.

9. Neff JA, Hoppe SK. Race/ethnicity, acculturation, and psychological distress: fatalism and religiosity as cultural resources. J Community Psychol. 1993;21(1):3-20.

10. Otero-Sabogal R, Stewart S, Sabogal F, Brown BA, Perez-Stable EJ. Access and attitudinal factors related to breast and cervical cancer rescreening: why are Latinas still underscreened? Health Edu Behav. 2003;30:337-59.

11. Hubbell FA, Chavez LR, Mishra SI, Valdez RB. Differing beliefs about breast cancer among Latinas and Anglo women. West J Med. 1996;164:405-9.

12. Perez-Stable EJ, Sabogal F, Otero-Sabogal R, Hiatt RA, McPhee SJ. Misconceptions about cancer among Latinos and Anglos. JAMA. 1992;268(22):3219-23.

13. Chavez LR, Hubbell FA, Mishra SI, Valdez RB. The influence of fatalism on self-reported use of Papanicolaou smears. Am J Prev Med. 1997;13:418-24.

14. Davison C, Frankel S, Smith GD. The limits of lifestyle: reassessing 'fatalism' in the popular culture of illness prevention. Soc Sci Med. 1992;34:675-85.

15. Williams DR, Jackson PB. Social sources of racial disparities in health. Health Aff. 2005;24(2):225-34.

16. Williams DR, Oths KS, Gravlee CC. Race and ethnicity in public health research: models to explain health disparities. Annu Rev Anthropol. 2005;34:231-52.

17. Freeman HP. Cancer in the socioeconomically disadvantaged. CA Cancer J Clin. 1989;39(5):266-88.

18. Powe BD. Fatalism among elderly African Americans. effects on colorectal cancer screening. Cancer Nurs. 1995;18:385-92.

19. Puschel K, Thompson B, Coronado G, Gonzalez K, Rain C, Rivera S. "If I feel something wrong, then I will get a mammogram": understanding barriers and facilitators for mammography screening among Chilean women. Fam Pract. 2010;27(1):85-92.

20. Florez KR, Aguirre AN, Villanueva Cruz IJ, Cespedes A, De La Cruz AA, Abraido-Lanza AE. Fatalism or destiny? aqualitative study and interpretative framework on Dominican women's breast cancer beliefs. J Immigr Minor Health. 2009;11(4):291-301.

21. Jennings KM. Getting a pap smear: focus group responses of African American and Latina women. Oncol Nurs Forum. 1997;24(5):827-35.

22. Luquis RR, Villanueva Cruz IJ. Knowledge, attitudes, and perceptions about breast cancer and breast cancer screening among Hispanic women residing in South Central Pennsylvania. J Community Health. 2006;31(1):25-42.

23. Goldman RE, Risica PM. Perceptions of breast and cervical cancer risk and screening among Dominicans and Puerto Ricans in Rhode Island. Ethn Dis. 2004;14(1):32-42.
24. Fernandez ME, Palmer RC, Leong-Wu CA. Repeat mammography screening among low-income and minority women: a qualitative study. Cancer Control. 2005;12 Suppl 2:77-83.

25. Natale-Pereira A, Marks J, Vega M, Mouzon D, Hudson SV, Salas-Lopez D. Barriers and facilitators for colorectal cancer screening practices in the Latino community: prespectives from community leaders. Cancer Control. 2008;15(2):157-65.

26. Niederdeppe J, Levy AG. Fatalistic beliefs about cancer prevention and three prevention behaviors. Cancer Epidemiol Biomark. 2007;16(5):998-1003.

27. Nelson K, Geiger AM, Mangione CM. Effect of health beliefs on delays in care for abnormal cervical cytology in a multi-ethnic population. J Gen Intern Med. 2002;17(9):709-16.

28. Chavez LR, Hubbell FA, McMullin JM, Martinez RG, Mishra SI. Understanding knowledge and attitudes about breast cancer. A cultural analysis. Arch Fam Med. 1995;4(2):145-52.

29. Carpenter V, Colwell B. Cancer knowledge, self-efficacy, and cancer screening behaviors among Mexican-American women. J Cancer Edu. 1995;10(4):217-22.

30. Schmidt C. Fatalism may fuel cancer-causing behaviors. J Natl Cancer Inst. 2007;99(16):1222-3.

31. Lantz PM, Dupuis L, Reding D, Krauska K, Lappe K. Peer discussions of cancer among Hispanic migrant workers. Public Health Rep. 1994;109(4):512-20.

32. Watts L, Joseph NVA, Gonzalez M, Munro E, Muzikansky A, Rauh-Hain JA, et al. Understanding barriers to cervical cancer screening among Hispanic women. Am J Obstet Gynecol. 2009;201(2):199.e1-9.e8.

33. Suarez L, Roche RA, Nichols D, Simpson DM. Knowledge, behavior and fears concerning breast and cervical cancer among older low-income Mexican-American women. Am J Prev Med. 1997;13(2):137-42.

34. Lagos VI, Perez MA, Ricker CN, Blazer KR, Santiago NM, Feldman $\mathrm{NV}$, et al. Social-cognitive aspects of underserved Latinas preparing to undergo genetic cancer risk assessment for hereditary breast and ovarian cancer. Pychooncology. 2008;17(8):774-82.

35. Flynn PM. Motivated breast cancer screening behavior and its cultural antecedents. Ph.D. dissertation. Loma Linda, CA: Loma Linda University 2006.

36. Pasick RJ, Burke NJ. A critical review of theory in breast cancer screening promotion across cultures. Annu Rev Public Health. 2008;29:351-68.

37. Gonzalez P. The design, construction, and testing of an instrument to measure Latina's health beliefs about cancer and screening. Ph. D. dissertation. Fort Collins, CO: Colorado State University 2008.

38. Reynolds D. Cervical cancer in Hispanic/Latino women. Clin J Oncol Nurs. 2004;8(2):146-50.

39. Haynes MO. Geriatric gynecological care of minorities. Clin Obstet Gynecol. 1996;39(4):946-58.

40. Austin LT, Ahmad F, McNally MJ, Stewart DE. Breast and cervical cancer screening in Hispanic women: a literature review using the health belief model. Womens Health Issues. 2002;12(3):122-8.

41. Laws MB, Mayo SJ. The Latina breast cancer control study, year one: factors predicting screening mammography utilization by urban Latina women in Massachusetts. J Community Health. 1998;23(4):251-67.

42. Fernandez ME, Tortolero-Luna G, Gold RS. Mammography and pap test screening among low-income foreign-born Hispanic women in USA. Cad Saúde Pública. 1998;14 Suppl 3:133-47.

43. Michielutte R, Diglan MB, Sharp PC, Boxley J, Wells HB. Skin cancer prevention and early detection practices in a sample of rural women. Prev Med. 1996;25(6):673-83.

44. Dettenborn L, DuHamel K, Butts G, Thompson H, Jandorf L. Cancer fatalism and its demographic correlates among African American and Hispanic women: effects on adherence to cancer screening. J Psychosoc Oncl. 2004;22(4):47-60. 
45. Powe BD, Cooper DL, Harmond LR, Mercado FE, Faulkenberry $\mathrm{R}$. Comparing knowledge of colorectal and prostate cancer among African American and Hispanic men. Cancer Nurs. 2009;32 (5):412-7.

46. Bello J. Acculturation, traditionalism and cultural beliefs among Hispanic women with a positive mammogram: The impact on care seeking behavior and disease stage in breast cancer. Ph.D. dissertation. New York, NY: New School of Social Research; 2002.

47. Teran L, Baezconde-Garbanati L, Marquez M, Castellanos E, Belkic K. On-time mammography screening with a focus on Latinas with low income: a proposed cultural model. Anticancer Res. 2007;27(6C):4325-38.

48. Behbakht K, Lynch A, Teal S, Degeest K, Massad S. Social and cultural barriers to Papanicolaou test screening in an urban population. Obstet Gynecol. 2004;104(6):1355-61.

49. Gorin SS. Correlates of colorectal cancer screening compliance among urban Hispanics. J Behav Med. 2005;28(2):125-37.

50. Lopez-McKee G, McNeill JA, Badder J, Morales P. Comparisons of factors affecting rrepeat mammography screening of lowincome Mexican American women. Oncol Nurs Forum. 2008;35:941-7.

51. Harmon MP, Castro FG, Coe K. Acculturation and cervical cancer: knowledge, beliefs, and behaviors of Hispanic women. Women Health. 1996;24(3):37-57.

52. Ramirez AG, Suarez L, Laufman L, Barroso C, Chalela P. Hispanic women's breast and cervical cancer knowledge, attitudes, and screening behaviors. Am J Health Promot. 2000;14 (5):292-300.

53. Napoles A. The effects of cultural factors on the health screening behaviors of Latina women. Ph.D. dissertation. Berkeley, CA: University of California, Berkeley; 1999.
54. Randolph WM, Freeman DH Jr, Freeman JL. Pap smear use in a population of older Mexican-American women. Women Health. 2002;36(1):21-31.

55. Cuellar I, Arnold B, Gonzalez G. Cognitive referents of acculturation: assessment of cultural constructs in Mexican Americans. J Community Psychol. 1995;23:339-56.

56. National Research Council. Multiple Origins, Uncertain Destinies: Hispanics and the American Future. Panel on Hispanics in the United States. The National Academies Press; 2006.

57. Gallo LC, Penedo FJ, de los Espinosa Monteros K, Arguelles W. Resiliency in the face of disadvantage: do Hispanic cultural characteristics protect health outcomes? J Pers. 2010;77(6):1707-46.

58. Khan LK, Sobal JMR. Acculturation, socioeconomic status, and obesity in Mexican Americans, Cuban Americans, and Puerto Ricans. Int J Obes Relat Metab Disord. 1997;21(2):91-6.

59. Bowie JV, Juon HSCJREM. Factors associated with overweight and obesity among Mexican Americans and Central Americans: results from the 2001 California Health Interview Survey. Prev Chron Dis. 2007;4(1):A10.

60. Keeley B, Wright L, Condit CM. Functions of health fatalism: Fatalistic talk as face saving, uncertainty management, stress relief and sense making. Sociol Health Ill. 2009;31(5):734-47.

61. Powe BD, Weinrich S. An intervention to decrease cancer fatalism among rural elders. Oncol Nurs Forum. 1999;26(3):583-8.

62. Straughan PT, Seow A. Fatalism reconceptualized: a concept to predict health screening behavior. J Gend Cult Health. 1998;3(2):85-100.

63. Egede LE, Bonadonna RJ. Diabetes self-management in African Americans: an exploration of the role of fatalism. Diab Educ. 2003;29(1):105-15.

64. Boone C, De Brabander B, Gerits P, Willeme P. Relation of scores on Rotter's I-E scale to short-term and long-term control expectancies and fatalism. Psychol Rep. 1990;66:1107-11. 